\title{
ÉTUDE DES VARIATIONS \\ DE PARAMĖTRES ANATOMIQUES ET ENDOCRINIENS \\ CHEZ L'ANGUILLE EUROPÉENNE (ANGUILLA ANGUILLA) \\ FEMELLE, SÉDENTAIRE ET D'AVALAISON : APPLICATION À LA CARACTÉRISATION DU STADE ARGENTÉ.
}

\author{
J. MARCHELIDON, N. LE BELLE, A. HARDY, B. VIDAL, M. SBAIHI, \\ E. BURZAWA-GÉRARD, M. SCHMITZ* et S. DUFOUR
}

\begin{abstract}
Laboratoire de Physiologie Générale et Comparée, Muséum National d'Histoire Naturelle, URA 90 CNRS, 7 rue Cuvier, 75231 Paris Cedex 05.

* adresse actuelle / present address : Department of Aquaculture, Swedish University of Agriculture, Umea, Suède.
\end{abstract}

\section{RÉSUMÉ}

L'argenture est une transformation complexe qui fait passer les anguilles de la phase de croissance juvénile, sédentaire (stade jaune) à la phase de migration d'avalaison (stade argenté), étape initiale de la migration de reproduction océanique. Cette étude a été réalisée de façon comparative sur des lots d'anguilles femelles sédentaires ou d'avalaison, de taille supérieure à $45 \mathrm{~cm}$, capturées en milieu naturel. Nous avons cherché à définir des critères de l'argenture en associant, pour la première fois, des paramètres endocriniens à des paramètres anatomiques. Les paramètres anatomiques analysés comprennent des caractères externes (poids et longueur du corps, index oculaire, 1O) et internes (rapport gonadosomatique, RGS et rapport tractus digestif-somatique, RTDS) et les paramètres endocriniens incluent des hormones impliquées dans la métamorphose (hormones thyroïdiennes, $T_{4}$ et $T_{3}$ ), la croissance (hormone de croissance, $G H$ ) et la reproduction (hormone gonadotrope, $\mathrm{GtH}$ ).

Chez les anguilles sédentaires, on observe un développement progressif des ovaires, corrélé à la croissance corporelle. L'augmentation du RGS s'accentue chez les anguilles d'avalaison $(\times 2,85)$, une valeur seuil $\geq 1,4 \%$ caractérisant le stade argenté. L'agrandissement de l'oeil est également un phénomène progressif, initié dès le stade jaune et corrélé au RGS. Comme le RGS, l'accroissement de I'IO s'accentue chez les anguilles d'avalaison $(x 2)$, une valeur seuil $\geq 8$ pouvant être proposée comme critère externe d'argenture. La régression du tractus digestif n'est pas initiée au stade jaune, et survient seulement à l'argenture $(x, 0,26)$, avec une valeur seuil $\leq 1,5 \%$ caractérisant le stade argenté. 
Parmi les paramètres endocriniens étudiés, seule la teneur hypophysaire en GtH permet de caractériser l'argenture. La teneur en GtH s'élève progressivement au cours du stade jaune, de façon corrélée avec le RGS, puis s'accroît fortement à l'argenture (x 25), une valeur seuil $\geq 15 \mathrm{ng} / \mathrm{hypophyse}$ permettant de caractériser le stade argente. La teneur hypophysaire en GH augmente au cours du stade jaune de façon corrélée avec la longueur du corps. La teneur en $\mathrm{GH}$ baisse à l'argenture $(x 0,5)$, mais le recoupement des valeurs individuelles ne permet pas d'utiliser ce critère. Le taux circulant d'hormone thyroïdienne $T_{4}$ augmente à l'argenture $(x, 1,38)$ mais avec un large recoupement des valeurs individuelles. Le taux de $\mathrm{T}_{3}$ ne varie pas à l'argenture.

En conclusion, l'argenture inclut des transformations multiples, caractéristiques aussi bien de la métamorphose (augmentation de $T_{4}$ ), de l'initiation de la puberté (augmentations du RGS et de GtH), du jeûne (diminution du RTDS) et de l'arrêt de croissance (diminution de GH). Certains paramètres anatomiques (IO, RGS, RTDS), et endocriniens $(\mathrm{GtH})$, qui présentent très peu de recoupement dans les valeurs individuelles entre les stades jaune et argenté, sont utilisables comme critères de l'argenture.

Mots-clés : anguille européenne, Anguilla anguilla, argenture, index oculaire, ovaires, tractus digestif, hormone gonadotrope, $\mathrm{GtH}$, hormone de croissance, $\mathrm{GH}$, hormones thyroïdiennes, $T_{3}, T_{4}$

\author{
STUDY OF VARIATIONS \\ OF ANATOMICAL AND ENDOCRINE PARAMETERS \\ IN SEDENTARY AND DOWNSTREAM MIGRATING FEMALE \\ EUROPEAN EELS (ANGUILLA ANGUILLA) : \\ APPLICATION TO THE CHARACTERIZATION OF THE SILVER STAGE.
}

\begin{abstract}
Silvering process in eels is a complex transformation from the sedentary phase of juvenile growth (yellow stage) to the downstream migratory phase (silver stage), which is the initial step of the reproductive oceanic migration. The present comparative study was performed on batches of sedentary or migratory female eels, body length $>45 \mathrm{~cm}$, caught in natural environment. We looked for criteria of silver stage by combining, for the first time, endocrine parameters to anatomical ones. Anatomical parameters included external characteristics (body weight, body length, ocular index, Ol) and internal ones (gonadosomatic index, GSI, digestive tract-somatic index, DTSI). Endocrine parameters included hormones implicated in metamorphosis (thyroid hormones, $T_{3}$ and $T_{4}$ ), growth (growth hormone, $\mathrm{GH}$ ) and reproduction (gonadotropic hormone, $\mathrm{GH} H$ ).
\end{abstract}

Sedentary eels show a progressive development of ovaries, correlated to body growth. GSI further increases in downstream migratory eels $(x 2.85)$, a threshold value $\geq 1,4 \%$ characterizing the silver stage. The enlargement of the eyes also is a progressive phenomenon, initiated at the yellow stage in correlation to the GSI. As well as for GSI, Of further increases in migratory eels $(x 2)$, a threshold value $\geq 8$ being proposed as an external criterion of silvering. Regression of the digestive tract is not initiated at the yellow stage and occurs at silvering, with a threshold value $\leq 1.5 \%$ characteristic of the silver stage. 
Among the endocrine parameters studied, only pituitary GtH content allows to characterize silvering. GtH content steadily increased at the yellow stage, in correlation to the GSI, then strongly raised $(x 25)$ in migratory eels, with a threshold value $\geq 15 \mathrm{ng} / \mathrm{hypophyse}$ characteristic of the silver stage. Pituitary GH content increases at the yellow stage, in correlation with body length. $\mathrm{GH}$ content drops at silvering $(\times 0.5)$, but the large overlapping of individual values does not allow to use this criterion. Circulating levels of thyroid hormone, $T_{4}$, increase at silvering $(x$ 1.38) but with a large overlapping of individual values. $T_{3}$ levels do not vary at silvering.

In conclusion, silvering includes multiple transformations, which are characteristic of metamorphosis (increase in $\mathrm{T}_{4}$ ) as well as of initiation of puberty (increases in GSI and $\mathrm{GtH}$ ), fasting (decrease in DTSI), and stop of growth (decrease in $\mathrm{GH}$ ). Some of these anatomical (OI, GSI, DTSI) and endocrine (GtH) parameters, which exhibit very few overlapping of individual values between yellow and silver eels, may be used as criteria of silvering.

Key-words : European eel, Anguilla anguilla, silvering, ocular index, ovaries, digestive tract, gonadotropin, $\mathrm{GtH}$, growth hormone, $\mathrm{GH}$, thyroid hormones, $\mathrm{T}_{3}, \mathrm{~T}_{4}$.

\section{INTRODUCTION}

Les menaces pesant actuellement sur le devenir des populations d'anguilles rendent urgente une politique de gestion de cette ressource et donc une connaissance approfondie de ses populations. Le cycle biologique de l'anguille est particulièrement complexe, même en ce qui concerne sa phase de vie dans les eaux continentales. Dans cette étude, nous avons recherché différents paramètres biométriques et physiologiques nécessaires à la caractérisation des écophases successives jaune et argentée.

L'aire de ponte présumée de l'anguille européenne (Anguilla anguilla L.) a été localisée en Atlantique Ouest dans la région de la mer des Sargasses par SCHMIDT (1922). Les larves pélagiques (leptocéphales) sont entraînées par les courants marins vers les côtes européennes et se métamorphosent en civelles au niveau du plateau continental (pour revue : TESCH, 1977 ; LECOMTE-FINIGER, 1984, 1994). Ces civelles pénètrent dans les estuaires (pour revue : ELIE et ROCHARD, 1994) et remontent les rivières où elles se transforment en anguillettes puis en anguilles jaunes. Ces dernières entament alors une période de croissance au cours de laquelle s'effectue la différentiation sexuelle (COLOMBO et al., 1984 ; COLOMBO et GRANDI, 1996).

A la fin de cette phase de croissance les anguilles jaunes subissent une seconde métamorphose qui les conduit à la phase de migration d'avalaison (stade argenté) (pour revue : FONTAINE, 1975 ; LECOMTE-FINIGER, 1990 ; FONTAINE, 1994). Ce stade est non seulement caractérisé par un changement de couleur de la peau mais aussi par des modifications au niveau de la musculature (PANKHURST, 1982b), du tractus digestif (SORENSEN et PANKHURST, 1988), des branchies (FONTAINE et al., 1995), de la vessie natatoire (KLECKNER, 1980 ; KLECKNER et KRUEGER, 1981), des organes sensoriels (PANKHURST, 1982a ; PANKHURST et LYTHGOE, 1983) et des gonades (FONTAINE, 1989 ; FONTAINE et DUFOUR, 1991 ; DUFOUR, 1994). Cette métamorphose qu'est l'argenture se mettrait en place pour des tailles corporelles moyennes supérieures à $35 \mathrm{~cm}$ chez les mâles et à $45 \mathrm{~cm}$ chez les femelles (pour revue : LECOMTE-FINIGER, 1990). Les âges correspondants, variables selon les sites géographiques, sont plus élevés chez les femelles que chez les mâles (VOLLESTAD et JONSSON, 1986 ; LECOMTE-FINIGER, 1990). Les anguilles argentées possédant certains caractères anatomo-sensoriels de poissons abyssaux, on peut considérer que 
cette métamorphose est une " adaptation d'anticipation " à la migration de reproduction en milieu océanique profond (FONTAINE, 1983 ; FONTAINE et al., 1985).

Le cycle vital des différentes espèces d'anguilles à travers le monde présente des caractéristiques similaires avec une phase de reproduction en milieu marin et une phase de croissance dans les eaux continentales. Cependant, des variations entre espèces ont été observées dans le développement des gonades au stade argenté. Ainsi, le poids des ovaires, de 1,5 à $2 \%$ du poids du corps chez la femelle de l'anguille européenne peut atteindre 3 à $5 \%$ chez les anguilles américaines (Anguilla rostrata), japonaises (Anguilla japonica) et australiennes (Anguilla australis) et jusqu'à $9 \%$ chez l'anguille néo-zélandaise (Anguilla dieffenbachii). Des différences similaires sont observées chez les mâles, le poids des testicules au stade argenté passant d'environ $0,1 \%$ du poids du corps chez Anguilla anguilla à 1,4\% chez Anguilla dieffenbachii (pour revue : DUFOUR, 1994).

BEULLENS et al. (1997a) ont montré que chez les anguilles européennes élevées en captivité depuis le stade civelle, la majorité des individus évolue vers le sexe mâle. Dans ces conditions d'élevage, les mâles s'argentent dès l'âge de 2 ans et pour des tailles comprises entre 35 et $58 \mathrm{~cm}$ et les femelles dès l'âge de 3-4 ans pour des tailles comprises entre 53 et $79 \mathrm{~cm}$. Ceci indique que la métamorphose se produirait plus tôt en captivité qu'en milieu naturel, mais pour des tailles plus élevées (BEULLENS et al., 1997b).

Ainsi, il semble que les conditions environnementales jouent un rôle important dans la mise en place de l'argenture et donc qu'il soit difficile d'extrapoler les résultats obtenus en captivité aux animaux vivant en milieu naturel. Nous avons donc entrepris une étude des variations des paramètres anatomiques internes et externes sur des populations naturelles d'anguilles européennes en fonction du stade jaune ou argenté, en associant pour la première fois aux paramètres anatomiques, des paramètres endocriniens de la métamorphose, de la croissance et de la reproduction.

\section{MATÉRIEL ET MÉTHODES}

\section{Animaux : capture, mesures et prélèvements}

Des anguilles sédentaires ont été capturées par pêche électrique dans la rivière Varenne (Seine-Maritime) en juillet et septembre 1994 ; seules les anguilles de taille $>45 \mathrm{~cm}$ (anguilles femelles) ont été conservées. Des anguilles d'avalaison (stade argenté) ont été capturées au filet à la sortie des étangs de Péronne (Somme), au moment du pic de migration d'avalaison en octobre 1994 ; ce lot ne comprenait que des anguilles de taille $>45 \mathrm{~cm}$ (anguilles femelles) et a été utilisé comme référence pour l'analyse des caractéristiques anatomiques et endocriniennes du stade argenté. Dès leur capture, les anguilles ont été transportées au Laboratoire et maintenues en aquarium en eau courante pendant 5-6 jours avant d'être sacrifiées ( 40 anguilles/lot). Hormis en ce qui concerne la taille $(>45 \mathrm{~cm})$ pour les lots sédentaires, aucun autre tri n'a été effectué sur les lots étudiés.

La mesure des paramètres anatomiques externes suivants est effectuée : le poids (P) et la longueur (L) du corps, le coefficient de condition ( $\left.\mathrm{K}=\% \mathrm{P} / \mathrm{L}^{3}\right)$, l'index oculaire $\left(I O=\left(\left(D_{h}+D_{v}\right) / 4\right)^{2} \times 3,14 / L\right)$ où $D_{h}$ et $D_{v}$ représentent respectivement les diamètres horizontaux et verticaux de l'œil (PANKHURST, 1982).

Les animaux sont sacrifiés et les paramètres anatomiques internes suivants sont mesurés : le rapport gonadosomatique (RGS $=\%$ poids de l'ovaire/P) et le rapport tractus digestif-somatique (RTDS $=\%$ poids du tractus digestif/P). 
Pour les analyses hormonales, des échantillons de sang sont prélevés et, après coagulation, les sérums sont conservés congelés à $-20^{\circ} \mathrm{C}$. Les hypophyses sont prélevées et congelées individuellement dans $500 \mu \mathrm{l}$ de $\mathrm{NaCl} 0,9 \%$. Les hormones hypophysaires sont extraites par éclatement des cellules par ultrasons $(2 \times 10 \mathrm{~s}$ au sonicateur) ; après centrifugation pendant $15 \mathrm{mn}$ à $11300 \mathrm{~g}$, les surnageants sont conservés congelés à $-20^{\circ} \mathrm{C}$ avant l'analyse.

\section{Dosages radioimmunologiques (RIA)}

Les concentrations sériques en hormones thyroïdiennes (thyroxine, $\mathrm{T}_{4}$ et triiodothyronine, $T_{3}$ ), hormones impliquées dans le contrôle du développement et en particulier des métamorphoses, ont été mesurées au moyen d'un RIA décrit par LELOUP et DE LUZE (1980).

L'hormone de croissance (GH), responsable du contrôle de la croissance corporelle, est mesurée dans les sérums et les extraits hypophysaires au moyen d'un RIA homologue mis au point au Laboratoire pour la GH d'anguille (MARCHELIDON et al., 1996).

L'hormone gonadotrope (GtH) de type 2, impliquée dans le contrôle de la reproduction, est mesurée dans les extraits hypophysaires au moyen d'un RIA développé au Laboratoire pour le dosage de la GtH de carpe (BURZAWA-GERARD et KERDELHUÉ, 1978) et validé pour le dosage de la GtH d'anguille (DUFOUR et al., 1983). Cette hormone est indétectable dans le sérum aux stades jaune et argenté (DUFOUR, 1994) et n'a donc pas été mesurée dans les échantillons sanguins.

\section{Analyses statistiques}

Les corrélations entre deux paramètres pour les valeurs individuelles ont été mises en évidence en utilisant le test de régression. Les niveaux de signification sur tes différences observées entre les valeurs moyennes ont été déterminés par analyse de variance à une seule entrée.

\section{RÉSULTATS}

\section{Poids (P) et longueur ( $L$ ) du corps}

La Figure 1 représente la relation existant entre le poids et la longueur du corps. Les longueurs du corps varient de 47 à $67 \mathrm{~cm}$, pour des poids de 167 à $495 \mathrm{~g}$. Une corrélation significative du type $P=2,7 \times 10^{-3} L^{2.87}$ est observée entre ces deux paramètres $(P<0,001$; $\left.r^{2}=0,84 ; d l=118\right)$. Cette relation est similaire pour les 3 lots d'anguilles. L'homogénéité des lots est confirmée par la comparaison $(P>0,70)$ des valeurs des coefficients de condition qui sont respectivement de $0,165 \pm 0,003$ pour les anguilles sédentaires de juillet, $0,160 \pm 0,002$ pour les anguilles sédentaires de septembre et de $0,166 \pm 0,003$ pour les anguilles d'avalaison.

\section{Rapport gonadosomatique (RGS)}

Pour les anguilles sédentaires, le RGS varie de 0,25 à 1,6\% (Figure 2), avec une moyenne de $0,67 \pm 0,03 \%$ (respectivement $0,61 \pm 0,04 \%$ pour le lot de juillet et $0,72 \pm 0,04 \%$ pour le lot de septembre, différence non significative). Pour l'ensemble de ces anguilles sédentaires, une corrélation positive significative est observée entre la longueur du corps et le RGS $\left(P<0,01 ; r^{2}=0,24 ; d l=78\right)$ (Figure 3a). 


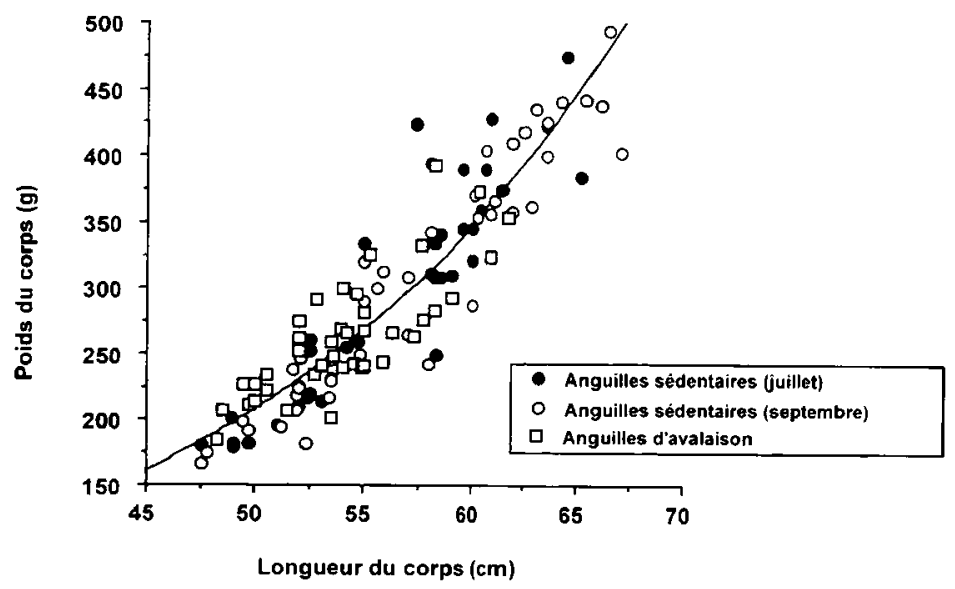

Figure 1

Relation entre le poids (P) et la longueur (L) du corps chez les anguilles femelles sédentaires (lots de juillet et septembre) et les anguilles femelles d'avalaison ( $n=40$ anguilles/lot). Une relation du type $P=a^{b}$ est trouvée pour l'ensemble des 3 lots.

\section{Figure 1}

Relation between body weight $(W)$ and body length $(L)$ of sedentary female eels (batches of July - and September $O$ ) and of downstream migrating female eels (J) ( $n=40$ eels/group). A relationship $W=a^{b}$ is found for all the 3 groups.

Poids du corps $(\mathbf{g})=$ Body weight $(\mathrm{g})$.

Longueur du corps $(\mathrm{cm})=$ Body length $(\mathrm{cm})$.

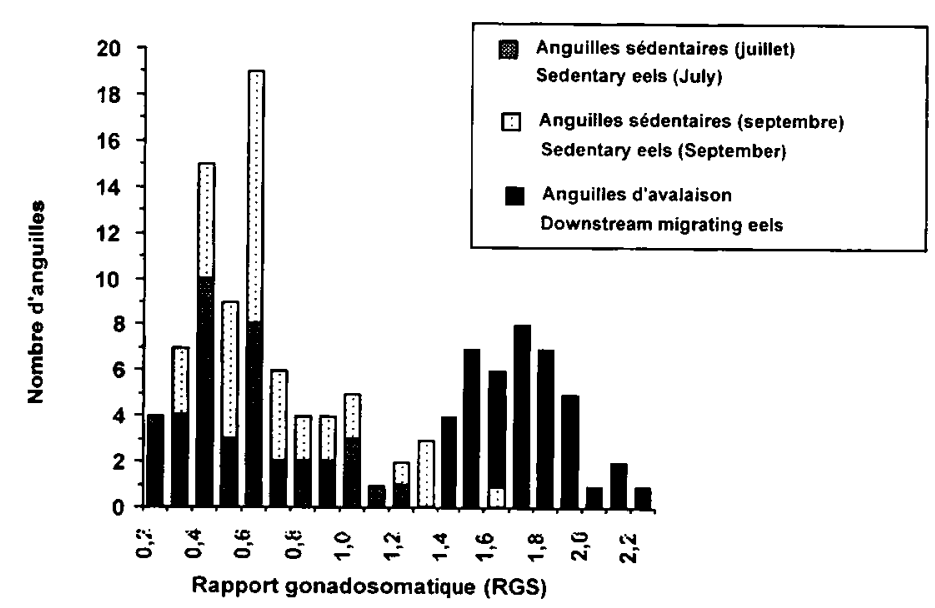

Figure 2

Histogramme représentant le nombre d'anguilles en fonction du rapport gonadosomatique (RGS) chez les anguilles femelles sédentaires (lots de juillet et septembre) et les anguilles femelles d'avalaison.

\section{Figure 2}

Histogram showing the number of sedentary female eels (batches of July and September) and downstream migrating female eels, as a function of the gonadosomatic index (GSI).

Rapport gonadosomatique (RGS) = Gonadosomatic index (GSI).

Nombre d'anguilles $=$ Number of eels. 

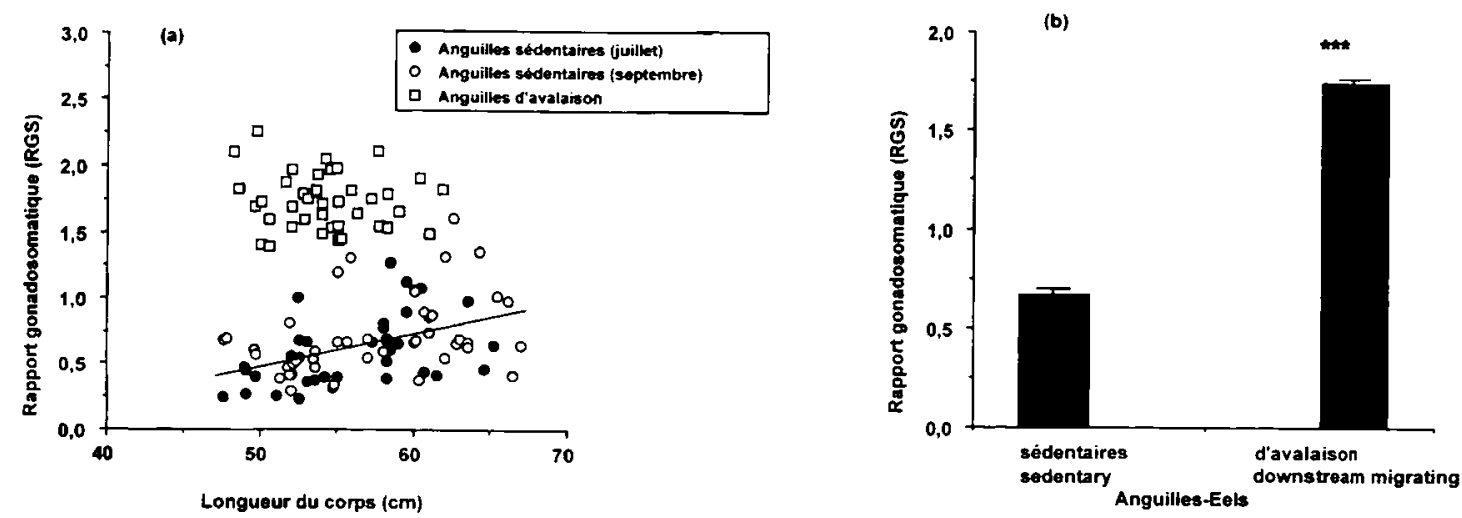

Figure 3

Variations du rapport gonadosomatique (RGS).

3a : Relation entre le rapport gonadosomatique (RGS) et la longueur du corps chez les anguilles femelles sédentaires (lots de juillet et septembre) et les anguilles femelles d'avalaison. Une corrélation significative $(p<0,01)$ est observée pour les anguilles sédentaires.

3b : Valeurs moyennes et erreurs standards des rapports gonadosomatiques (RGS) des anguilles femelles sédentaires $(n=80)$ et des anguilles femelles d'avalaison $(n=40)\left({ }^{* \star *}\right.$ : augmentation significative; $\left.p<0,001\right)$.

\section{Figure 3}

Variations of the gonadosomatic index (GSI).

3a : Relation between gonadosomatic index (GSI) and body length of sedentary female eels (batches of July - and September $O$ ) and downstream migrating female eels ( () . A significant correlation $(p<0.01)$ is observed for the sedentary eels.

Longueur du corps $(\mathrm{cm})=$ Body length $(\mathrm{cm})$.

Rapport gonadosomatique (RGS) = Gonadosomatic index (GSI).

3b : Means and standard errors of gonadosomatic index (GSI) of sedentary female eels $(n=80)$ and downstream migrating female eels $(n=40)$ $(* \star \star$ : significant increase $; p<0.001)$.

Rapport gonadosomatique $($ RGS $)=$ Gonadosomatic index $(G S I)$

Les anguilles d'avalaison présentent un RGS compris entre 1,4 et 2,2\% (Figure 2), avec une moyenne de $1,74 \pm 0,03 \%$, significativement supérieure au RGS des anguilles sédentaires ( $x 2,85 ; p<0,001)$ (Figure $3 b)$. Pour les anguilles d'avalaison, aucune corrélation n'est observée entre le RGS et la longueur du corps (Figure 3a).

Parmi les anguilles sédentaires, une seule, capturée en septembre, a un RGS $(1,6 \%)$ recoupant les valeurs des anguilles argentées d'avalaison.

\section{Index oculaire (IO)}

Les anguilles sédentaires ont un 10 compris entre 3,4 et 6,5 , avec une valeur moyenne égale à $4,9 \pm 0,08$ (Figures $4 a$, b). Pour l'ensemble de ces anguilles sédentaires, une corrélation positive significative est observée entre l'lO et le RGS ( $p<0,01$; $r^{2}=0,197 ; d l=78$ ) (Figure 4a). 

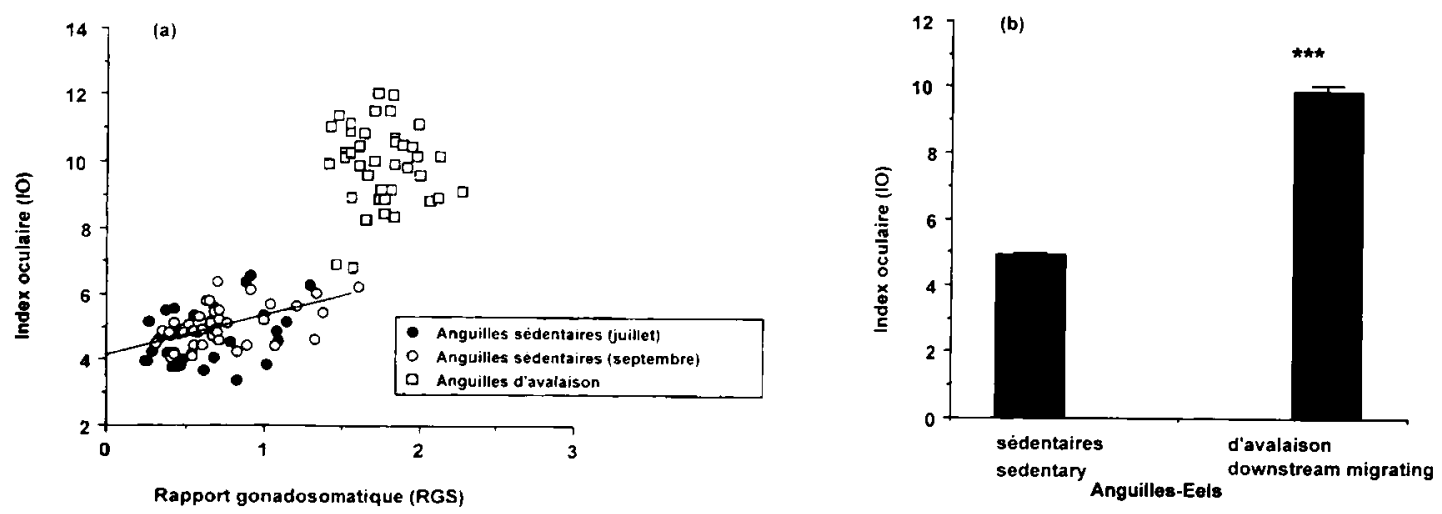

Figure 4

Variations de l'index oculaire (IO).

4a : Relation entre l'index oculaire (IO) et le rapport gonadosomatique (RGS) chez les anguilles femelles sédentaires (lots de juillet et septembre) et les anguilles d'avalaison. Une corrélation significative $(p<0,01)$ est observée pour les anguilles sédentaires.

4b : Valeurs moyennes et erreurs standards des index oculaires (10) des anguilles femelles sédentaires $(n=80)$ et des anguilles femelles d'avalaison $(n=40)\left(^{\star \star \star}\right.$ : augmentation significative $\left.; p<0,001\right)$.

\section{Figure 4}

Variations of the ocular index (OI).

4a : Relation between ocular index (OI) and gonadosomatic index (GSI) of sedentary female eels (batches of July - and September $)$ ) and downstream migrating female eels $(\sqsupset)$. A significant correlation $(p<0.01)$ is observed for the sedentary eels.

Rapport gonadosomatique (RGS) = Gonadosomatic index (GSI).

Index oculaire $(\mathrm{IO})=$ Ocular index (OI).

4b : Means and standard errors of ocular index (OI) of sedentary female eels $(n=80)$ and of downstream migrating female eels $(n=40)\left({ }^{\star \star \star}\right.$ : significant increase ; $p<0.001)$.

Index oculaire $(\mathrm{IO})=$ Ocular index (OI).

Les anguilles d'avalaison ont un 10 compris entre 6,8 et 12 , avec une valeur moyenne égale à $9,9 \pm 0,19$, significativement supérieure à celle des anguilles sédentaires $(\times 2 ; p<0,001)$ (Figures $4 a, b)$.

\section{Rapport tractus digestif-somatique (RTDS)}

Les anguilles sédentaires ont un RTDS compris entre 2 et $5,6 \%$, avec une valeur moyenne égale à $3,5 \pm 0,08 \%$ (Figures $5 \mathrm{a}$, b). Pour l'ensemble de ces anguilles sédentaires, aucune corrélation n'est observée entre le RTDS et le RGS (Figure 5a).

Les anguilles d'avalaison ont un RTDS compris entre 0,49 et $1,39 \%$, avec une valeur moyenne égale à $0,9 \pm 0,03 \%$, significativement inférieure à celle des anguilles sédentaires $(x 0,26 ; p<0,001)$ (Figures $5 a, b)$. 

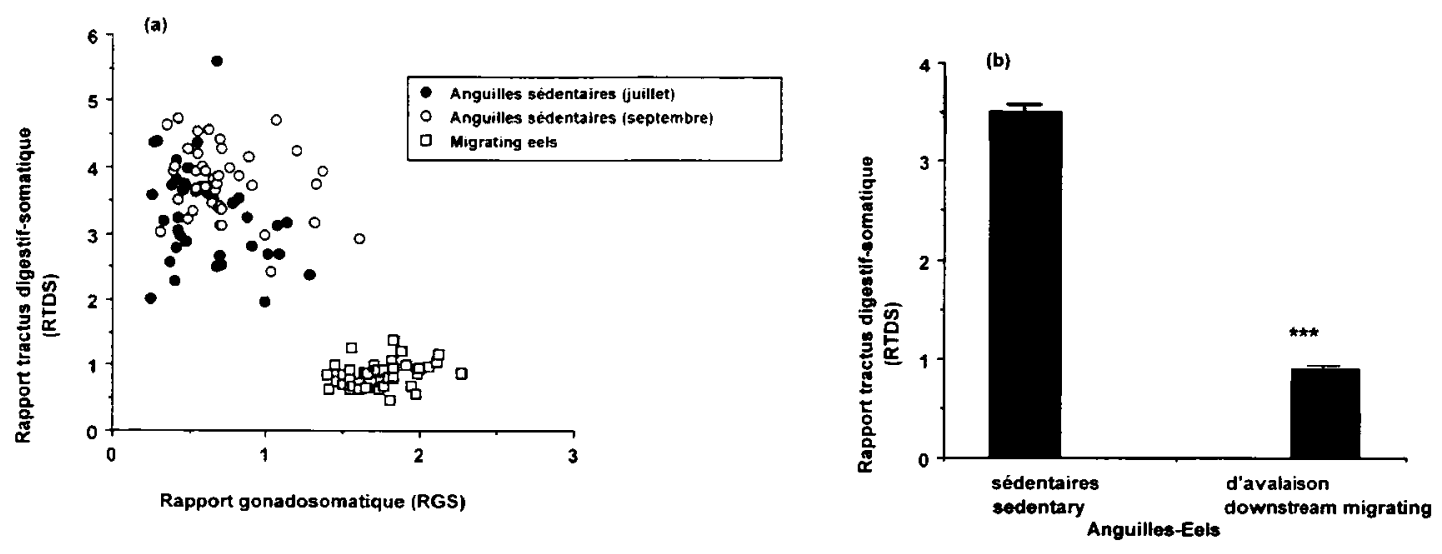

Figure 5

Variations du rapport tractus digestif-somatique (RTDS).

5a : Relation entre le rapport tractus digestif-somatique (RTDS) et le rapport gonadosomatique (RGS) chez les anguilles femelles sédentaires (lots de juillet et septembre) et les anguilles femelles d'avalaison.

$5 b$ : Valeurs moyennes et erreurs standards des rapports tractus digestif-somatique (RTDS) chez les anguilles femelles sédentaires $(n=80)$ et d'avalaison $(n=40)\left(^{\star \star \star}\right.$ : diminution significative $\left.; p<0,001\right)$.

\section{Figure 5}

Variations of the digestive tract-somatic index (DTSI).

5a : Relation between digestive tract-somatic index (DTSI $=\%$ of the digestive tract weight/body weight) and gonadosomatic index (GSI) of sedentary female eels (batches of July $\bullet$ and September $)$ ) and downstream migrating female eels (Ј).

Rapport gonadosomatique (RGS) = Gonadosomatic index (GSI).

Rapport tractus digestif-somatique (RTDS) = Digestive tract-somatic index (DTSI).

5b : Means and standard errors of DTSI of sedentary female eels $(n=80)$ and downstream migrating female eels $(n=40)\left({ }^{* \star \star}\right.$ : significant decrease $\left.; p<0.001\right)$. Rapport tractus digestif-somatique (RTDS) = Digestive tract-somatic index (DTSI).

\section{Concentrations sériques de thyroxine $\left(T_{4}\right)$ et de triiodothyronine $\left(T_{3}\right)$}

Les anguilles sédentaires ont des concentrations sériques de $T_{4}$ comprises entre 1,3 et $31,3 \mathrm{ng} / \mathrm{ml}$, avec une valeur moyenne égale à $12,5 \pm 0,63 \mathrm{ng} / \mathrm{ml}$ (Figures $6 \mathrm{a}, \mathrm{c}$ ) et de $T_{3}$ comprises entre 1,7 et $17,8 \mathrm{ng} / \mathrm{ml}$, avec une valeur moyenne égale à $9,1 \pm 0,33 \mathrm{ng} / \mathrm{ml}$ (Figures 6b, c). Aucune corrélation avec le RGS (Figures 6a, b), ni avec la longueur du corps, n'est observée.

Les anguilles d'avalaison ont une concentration sérique de $T_{4}$ comprise entre 4,7 et $32 \mathrm{ng} / \mathrm{ml}$, avec une valeur moyenne égale à $17,3 \pm 1,11 \mathrm{ng} / \mathrm{ml}$, significativement supérieure à celle des anguilles sédentaires ( $x 1,38 ; p<0,001$ ) (Figures $6 a, c)$. Cependant un très haut degré de recoupement des valeurs individuelles de $T_{4}$ est trouvé entre les anguilles sédentaires et migrantes ( $96 \%$ des valeurs individuelles).

Les anguilles d'avalaison ont une concentration sérique de $T_{3}$ comprise entre 5,5 et $13,9 \mathrm{ng} / \mathrm{ml}$, avec une valeur moyenne égale à $9,4 \pm 0,32 \mathrm{ng} / \mathrm{ml}$, sans différence significative avec celle des anguilles sédentaires (Figures $6 b, c)$. 

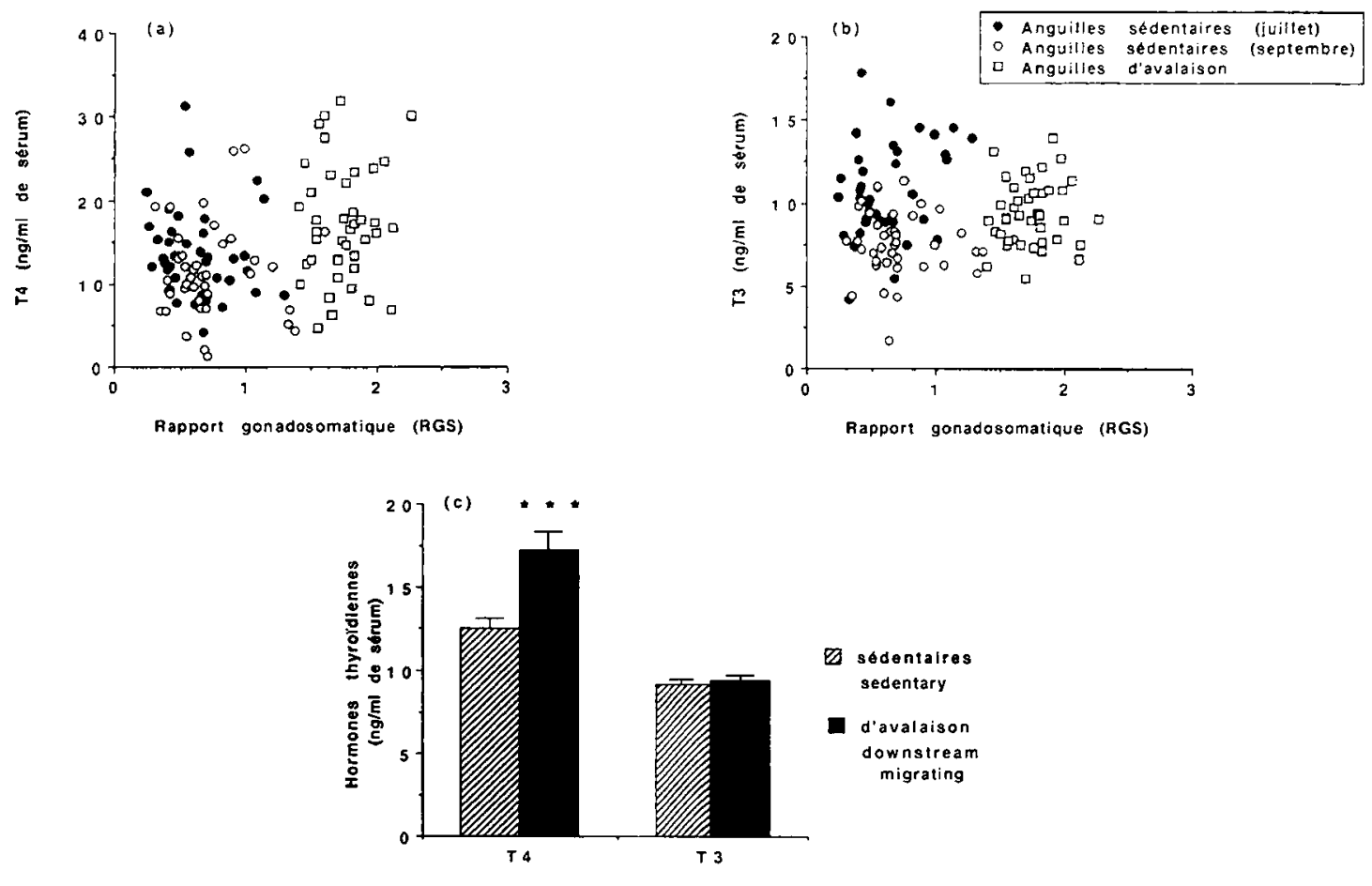

Figure 6

Variations des teneurs sériques en hormones thyroïdiennes, thyroxine $\left(T_{4}\right)$ et triiodothyronine $\left(T_{3}\right)$.

6a : Relation entre la concentration de thyroxine $\left(T_{4}\right)$ sérique et le rapport gonadosomatique (RGS) chez les anguilles femelles sédentaires (lots de juillet et septembre) et les anguilles femelles d'avalaison.

6b : Relation entre la concentration de triiodothyronine $\left(T_{3}\right)$ sérique et le rapport gonadosomatique (RGS) chez les anguilles femelles sédentaires (lots de juillet et septembre) et les anguilles femelles d'avalaison.

6c : Valeurs moyennes et erreurs standards des concentrations sériques en thyroxine $\left(T_{4}\right)$ et triiodothyronine $\left(T_{3}\right)$ chez les anguilles femelles sédentaires $(n=80)$ et les anguilles femelles d'avalaison $(n=40)\left({ }^{\star \star \star}:\right.$ augmentation significative $; p<0,001$ ).

\section{Figure 6}

Variations of serum levels of thyroid hormones, thyroxine $\left(T_{4}\right)$ and triiodothyronine $\left(T_{3}\right)$.

6a : Relation between thyroxine ( $\left.\mathrm{T}_{4}\right)$ serum level and gonadosomatic index (GSI) of sedentary female eels (batches of July $\bullet$ and September $)$ ) and downstream migrating female eels (ఏ).

Rapport gonadosomatique (RGS) = Gonadosomatic index (GSI).

$T_{4}(\mathrm{ng} / \mathrm{ml}$ de sérum $)=T_{4}(\mathrm{ng} / \mathrm{ml}$ serum$)$.

6b : Relation between triiodothyronine $\left(\mathrm{T}_{3}\right)$ serum level and gonadosomatic index (GSI) of sedentary female eels (batches of July - and September )) and downstream migrating female eels (Ј).

Rapport gonadosomatique (RGS) = Gonadosomatic index (GSI).

$T_{3}(\mathrm{ng} / \mathrm{ml}$ de sérum $)=T_{3}(\mathrm{ng} / \mathrm{ml}$ serum $)$.

6c : Means and standard errors for thyroxine $\left(T_{4}\right)$ and triiodothyronine $\left(T_{3}\right)$ serum levels in sedentary female eels $(n=80)$ and downstream migrating female eels $(n=40)\left({ }^{\star \star \star}\right.$ : significant increase $\left.; p<0.001\right)$.

Hormones thyroïdiennes $(\mathrm{ng} / \mathrm{ml}$ de sérum) $=$ Thyroid hormones $(\mathrm{ng} / \mathrm{ml}$ serum). 


\section{Concentrations sériques et hypophysaires en hormone de croissance (GH)}

Les anguilles sédentaires ont une concentration sérique de $\mathrm{GH}$ comprise entre 1,07 et $9,5 \mathrm{ng} / \mathrm{ml}$, avec une valeur moyenne égale à $4,2 \pm 0,16 \mathrm{ng} / \mathrm{ml}$ et les anguilles d'avalaison ont une concentration sérique de GH comprise entre 0,87 et $15,1 \mathrm{ng} / \mathrm{ml}$, avec une valeur moyenne égale à $4,2 \pm 0,36 \mathrm{ng} / \mathrm{ml}$; aucune différence n'est trouvée entre les anguilles sédentaires et migrantes (Figures $7 a, b, c)$. Aucune corrélation n'est observée entre la teneur en GH sérique et la longueur du corps (Figure 7a) ni avec le RGS (Figure 7b).

En ce qui concerne la teneur hypophysaire en $\mathrm{GH}$, les anguilles sédentaires ont des valeurs comprises entre 27,1 et $177,8 \mu \mathrm{g}$ /hypophyse, avec une valeur moyenne égale à $82,5 \pm 3,74 \mu \mathrm{g} /$ hypophyse (Figures $8 \mathrm{a}, \mathrm{b}, \mathrm{c}$ ). Une corrélation positive significative est observée entre la teneur hypophysaire en $G H$ et la longueur du corps $\left(p<0,01 ; r^{2}=0,18\right.$; $\mathrm{dl}=78$ ) (Figure 8a) mais pas avec le RGS (Figure 8b).

Les anguilles d'avalaison ont une teneur hypophysaire en $\mathrm{GH}$ comprise entre 4,7 et $72,1 \mu \mathrm{g} /$ hypophyse, avec une valeur moyenne égale à $40,8 \pm 2,5 \mu \mathrm{g} /$ hypophyse (Figures $8 a, b, c)$. Une diminution significative $(x 0,5 ; p<0,001)$ de la teneur hypophysaire en $\mathrm{GH}$ est observée entre les valeurs moyennes des anguilles sédentaires et migrantes (Figure $8 \mathrm{c}$ ) ; cependant le degré de recoupement des valeurs individuelles est important (52\% des valeurs individuelles).

\section{Concentration hypophysaire de l'hormone gonadotrope (GtH)}

La teneur hypophysaire de GtH est beaucoup plus faible que celle de la $\mathrm{GH}$ (d'un facteur 1000 ) et la teneur circulante de GtH est indétectable par le RIA.

Les anguilles sédentaires ont une teneur hypophysaire de GtH comprise entre 0,26 et $11,96 \mathrm{ng} /$ hypophyse, avec une valeur moyenne égale à $2,1 \pm 0,26 \mathrm{ng} /$ hypophyse (Figures $9 a, b, c)$. Une corrélation positive significative est observée entre la teneur hypophysaire en GtH et la longueur du corps $\left(p<0,01 ; r^{2}=0,23 ; d l=78\right)$ et le RGS $\left(p<0,01 ; r^{2}=0,245 ; d l=78\right)$.

Les anguilles d'avalaison ont une teneur hypophysaire de GtH comprise entre 9,1 et 133,6 ng/hypophyse avec une valeur moyenne égale à $51,4 \pm 4,17 \mathrm{ng} / \mathrm{hyp}$ pophyse (Figures 9a, b, c). Une augmentation significative $(\times 25 ; p<0,001)$ est trouvée entre les anguilles sédentaires et migrantes (Figure $9 \mathrm{c}$ ). De plus, un très faible degré de recoupement est observé $(2,5 \%$ des valeurs individuelles). 

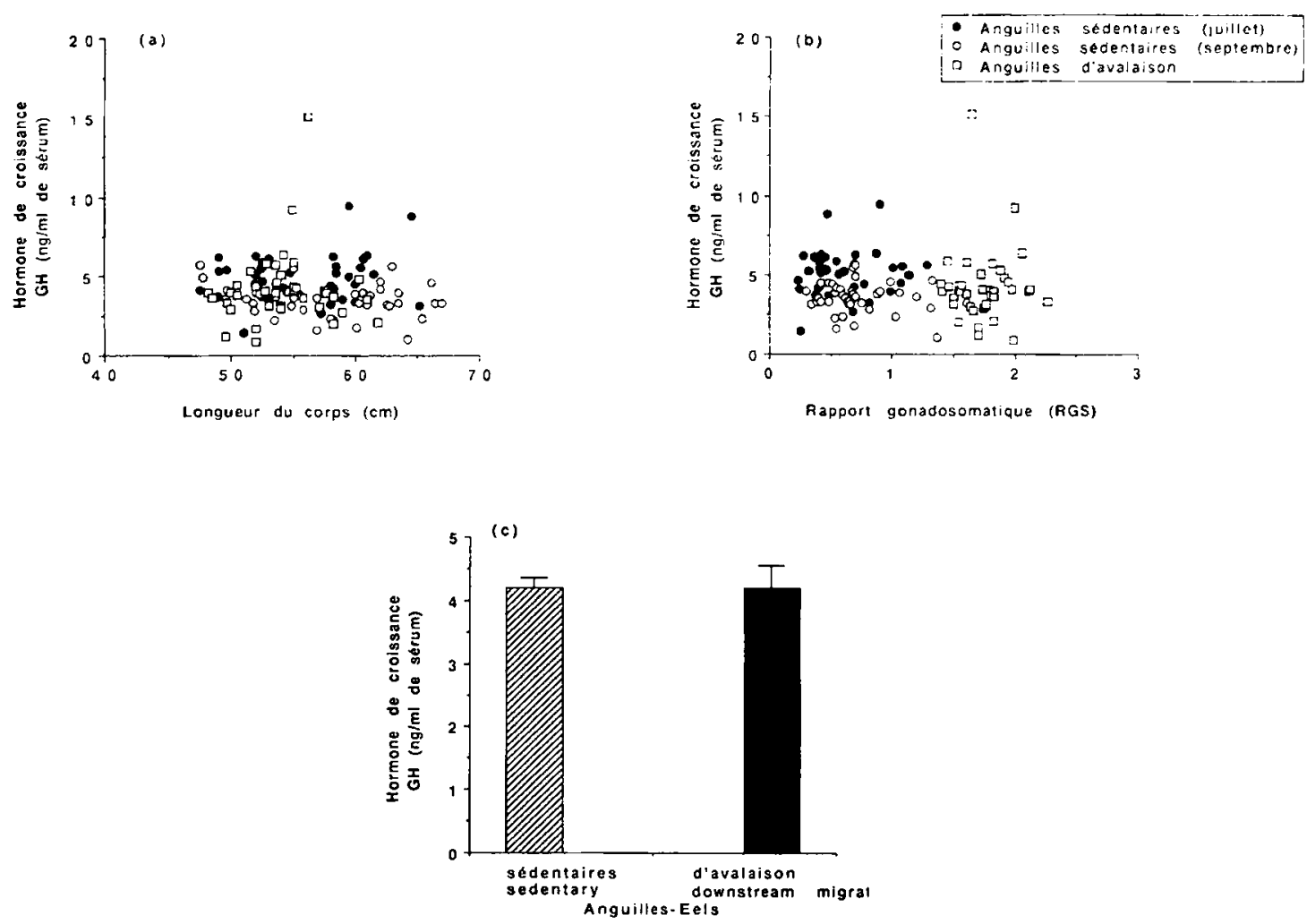

Figure 7

Variations de la teneur sérique en hormone de croissance, $\mathrm{GH}$.

$7 a$ : Relation entre la concentration sérique en hormone de croissance $(\mathrm{GH})$ et la longueur du corps chez les anguilles femelles sédentaires (lots de juillet et septembre) et les anguilles femelles d'avalaison.

$7 b$ : Relation entre la concentration sérique en hormone de croissance $(\mathrm{GH})$ et le rapport gonadosomatique (RGS) chez les anguilles femelles sédentaires capturées en juillet et septembre et les anguilles d'avalaison.

7c : Valeurs moyennes et erreur standard des concentrations sériques en hormone de croissance $(\mathrm{GH})$ chez les anguilles femelles sédentaires $(n=80)$ et les anguilles femelles d'avalaison $(n=40)$.

Figure 7

Variations of serum levels of growth hormone (GH).

7a : Relation between growth hormone (GH) serum level and body length of sedentary female eels (batches of July - and September )) and downstream migrating female eels $(\square)$.

Longueur du corps $(\mathrm{cm})=$ Body length $(\mathrm{cm})$.

Hormone de croissance $(\mathrm{ng} / \mathrm{ml}$ de sérum) = Growth hormone ( $\mathrm{ng} / \mathrm{ml}$ serum).

$7 b$ : Relation between growth hormone $(\mathrm{GH})$ serum level and gonadosomatic index (GSI) of sedentary female eels (batches of July $\bullet$ and September )) and downstream migrating female eels ( $($ ).

Rapport gonadosomatique (RGS) = Gonadosomatic index (GSI).

Hormone de croissance $(\mathrm{ng} / \mathrm{ml}$ de sérum) = Growth hormone ( $\mathrm{ng} / \mathrm{ml}$ serum).

7c : Means and standard errors of growth hormone (GH) serum levels in sedentary female eels $(n=80)$ and downstream migrating female eels $(n=40)$.

Hormone de croissance $(\mathrm{ng} / \mathrm{ml}$ de sérum $)=$ Growth hormone $(\mathrm{ng} / \mathrm{ml}$ serum). 

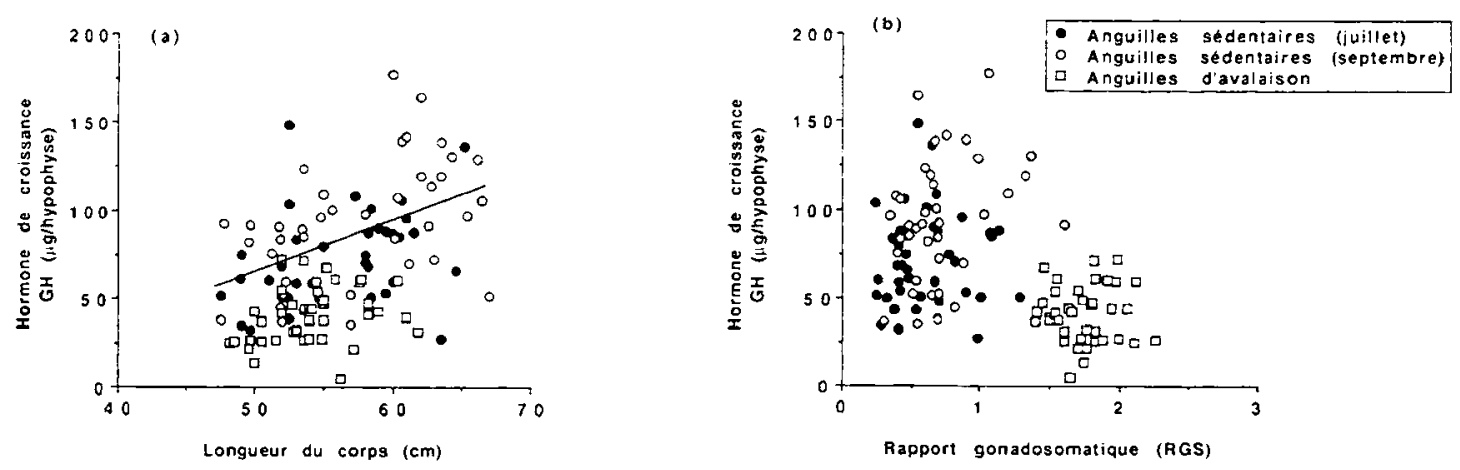

Figure 8

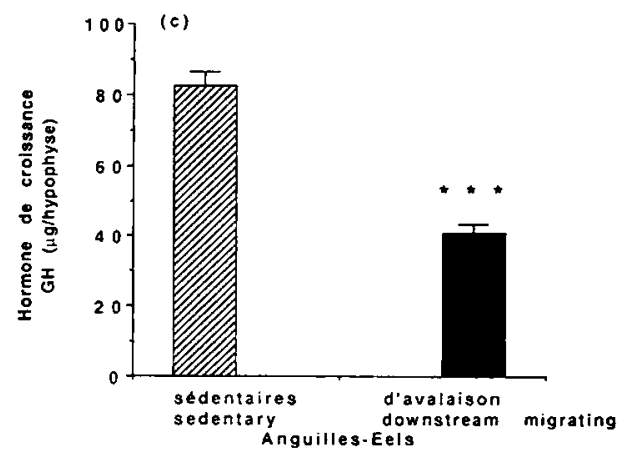

Variations de la teneur hypophysaire en hormone de croissance (GH).

8a : Relation entre la teneur hypophysaire en hormone de croissance (GH) et la longueur du corps chez les anguilles femelles sédentaires (lots de juillet et septembre) et les anguilles femelles d'avalaison. Une corrélation significative $(p<0,01)$ est observée chez les anguilles sédentaires.

$8 b$ : Relation entre la teneur hypophysaire en hormone de croissance (GH) et le rapport gonadosomatique (RGS) chez les anguilles femelles sédentaires (lots de juillet et septembre) et les anguilles femelles d'avalaison.

8c : Valeurs moyennes et erreurs standards des teneurs hypophysaires en hormone de croissance (GH) chez les anguilles femelles sédentaires $(n=80)$ et les anguilles femelles d'avalaison $(n=40)\left(^{\star \star \star}\right.$ : diminution significative; $p<0,001$ ).

\section{Figure 8}

Variations of pituitary levels of growth hormone (GH).

$8 \mathrm{a}$ : Relation between growth hormone $(\mathrm{GH})$ pituitary level and body length of sedentary female eels (batches of July - and September $\supset$ ) and downstream migrating female eels $(J)$. A significant correlation $(p<0.01)$ is observed for the sedentary eels.

Longueur du corps $(\mathrm{cm})=$ Body length $(\mathrm{cm})$.

Hormone de croissance $(\mu \mathrm{g} /$ hypophyse $)=$ Growth hormone ( $\mu \mathrm{g} / \mathrm{pituitary})$.

$8 \mathrm{~b}$ : Relation between growth hormone $(\mathrm{GH})$ pituitary level and gonadosomatic index (GSI) of sedentary female eels (batches of July $\bullet$ and September $\supset$ ) and downstream migrating female eels (Ј).

Rapport gonadosomatique (RGS) = Gonadosomatic index (GSI).

Hormone de croissance ( $\mu \mathrm{g} / \mathrm{hypophyse})=$ Growth hormone ( $\mu \mathrm{g} / \mathrm{pituitary}$ ).

$8 \mathrm{c}$ : Means and standard errors of growth hormone (GH) pituitary levels in sedentary female eels $(n=80)$ and downstream migrating female eels $(n=40)$ $\left({ }^{\star \star \star}\right.$ : significant decrease $\left.; p<0.001\right)$.

Hormone de croissance ( $\mu \mathrm{g} / \mathrm{hypophyse})=$ Growth hormone ( $\mu \mathrm{g} / \mathrm{pituitary}$ ). 

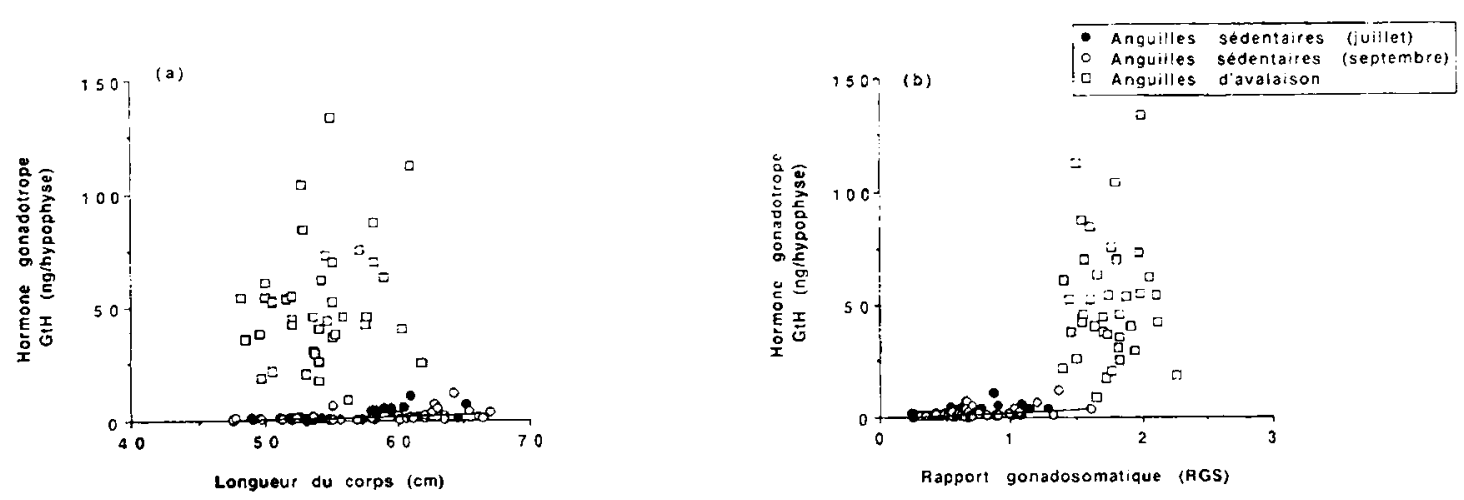

Figure 9

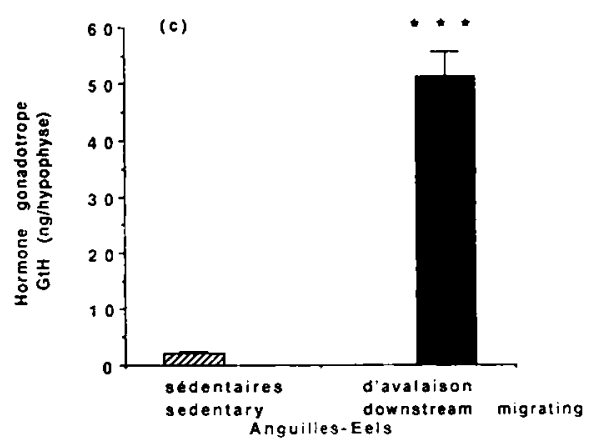

Variations de la teneur hypophysaire en hormone gonadotrope (GtH).

9a : Relation entre la teneur hypophysaire en hormone gonadotrope (GtH) et la longueur du corps chez les anguilles femelles sédentaires capturées en juillet et septembre et les anguilles d'avalaison. Une corrélation significative $(p<0,01)$ est observée chez les anguilles sédentaires.

$9 b$ : Relation entre la teneur hypophysaire en hormone gonadotrope (GtH) et le rapport gonadosomatique (RGS) chez les anguilles femelles sédentaires (lots de juillet et septembre) et les anguilles femelles d'avalaison. Une corrélation significative $(p<0,01)$ est observée chez les anguilles sédentaires.

9c : Valeurs moyennes et erreurs standards des teneurs hypophysaires en hormone gonadotrope (GtH) chez les anguilles femelles sédentaires $(n=80)$ et les anguilles femelles d'avalaison $(n=40)\left(^{\star \star \star}\right.$ : augmentation significative ; $p<0,001$ ).

Figure 9

Variations of pituitary levels of gonadotropic hormone (GtH).

9a : Relation between gonadotropic hormone (GtH) pituitary level and body length of sedentary female eels (batches of July $\bullet$ and September $O$ ) and downstream migrating female eels (J). A significant correlation $(p<0.01)$ is observed for the sedentary eels.

Longueur du corps $(\mathrm{cm})=$ Body length $(\mathrm{cm})$.

Hormone gonadotrope (ng/hypophyse) = Gonadotropic hormone (ng/pituitary).

9b : Relation between gonadotropic hormone (GtH) pituitary level and gonadosomatic index (GSI) of sedentary female eels (batches of July and September ) and downstream migrating female eels (J). A significant correlation $(p<0.01)$ is observed for the sedentary eels.

Rapport gonadosomatique (RGS) = Gonadosomatic index (GSI).

Hormone gonadotrope (ng/hypophyse) = Gonadotropic hormone (ng/pituitary).

9c : Means and standard errors of gonadotropic hormone (GtH) pituitary levels in sedentary female eels $(n=80)$ and downstream migrating female eels $(n=40)$ ${ }^{\star \star \star}$ : significant increase $\left.; p<0.001\right)$.

Hormone gonadotrope (ng/hypophyse) = Gonadotropic hormone (ng/pituitary). 


\section{DISCUSSION}

La comparaison des lots d'anguilles femelles (taille $>45 \mathrm{~cm}$ ) sédentaires et d'avalaison nous a permis de dégager les variations de paramètres anatomiques et endocriniens caractéristiques de l'argenture. Le lot d'anguilles d'avalaison a été pris comme référence pour le stade argenté.

Nous nous sommes attachés à ètudier différents paramètres afin de mieux comprendre les transformations anatomiques et physiologiques qui s'effectuent lors de l'argenture et d'obtenir des outils pour caractériser le stade argenté dans le cadre d'études de populations sur le terrain.

\section{Paramètres anatomiques}

\section{Développement ovarien}

Le développement ovarien est évalué par la mesure du rapport gonadosomatique (RGS). Chez les anguilles sédentaires, il varie de 0,25 à 1,6\%, son augmentation étant corrélée à la longueur du corps, même dans le cadre de la gamme restreinte de tailles étudiées $(47-67 \mathrm{~cm})$. Une augmentation significative $(p<0,001)$ du RGS est observée lors de l'argenture, la valeur moyenne passant de $0,67 \pm 0,03 \%$ chez les anguilles sédentaires à $1,74 \pm 0,03 \%$ chez les anguilles d'avalaison.

L'augmentation progressive du RGS avec la longueur du corps chez les anguilles sédentaires indique que le développement ovarien est un phénomène graduel initié au stade jaune en relation avec la croissance corporelle. Le développement ovarien s'accélère ensuite à l'argenture pour atteindre un plateau avec une valeur maximale d'environ 2,2 \% pour l'espèce européenne. Le RGS à l'argenture est cependant encore très éloigné des valeurs observées lors des maturations sexuelles expérimentales (40 à $60 \%$; FONTAINE et al., 1964).

Très peu de recoupement $(<1 \%$ ) des valeurs individuelles de RGS est observé entre les anguilles sédentaires et migrantes. Une valeur seuil $\geq 1,4 \%$ peut être proposée comme critère d'argenture avec un haut degré de fiabilité (100\% des anguilles d'avalaison, $1,25 \%$ des anguilles sédentaires).

La stimulation du développement gonadique lors de l'argenture est un phénomène largement décrit chez toutes les espèces d'anguilles (voir Introduction), qui confère à cette “ métamorphose " des caractéristiques d'initiation de la "puberté " (DUFOUR, 1994). Ces caractéristiques prépubertaires, propres à l'argenture, s'ajoutent aux transformations liées à la préparation, à la migration océanique et retrouvées dans la smoltification chez les salmonidés (telles que les modifications de la livrée et de l'épithélium branchial).

\section{Régression du tractus digestif}

La régression du tractus digestif est évaluée par la mesure du rapport tractus digestif-somatique (RTDS). Les anguilles sédentaires ont un RTDS compris entre 2 et $5,6 \%$, sans relation avec la longueur du corps ni avec le RGS. Une diminution significative $(p<0,001)$ du RTDS est observée lors de l'argenture, la valeur moyenne passant de $3,5 \pm 0,08 \%$ chez les anguilles sédentaires à $0,9 \pm 0,03 \%$ chez les anguilles d'avalaison. A la différence du développement ovarien qui commence au stade jaune, la régression du tractus digestif se met en place seulement à l'argenture. 
Aucun recoupement des valeurs individuelles de RTDS n'est observé entre les anguilles sédentaires et migrantes. Une valeur seuil $\leq 1,5 \%$ peut être proposée comme critère d'argenture avec un haut degré de fiabilité (100\% des anguilles d'avalaison, $0 \%$ des anguilles sédentaires).

La régression du tractus digestif chez les anguilles argentées, en relation avec l'installation d'un jeûne physiologique, est un phénomène qui s'accentue encore davantage lors des maturations expérimentales (SORENSEN et PANKHURST, 1988). Cette régression de l'intestin ne semble cependant pas irréversible, puisque des anguilles ayant subi une maturation expérimentale sont capables de se réalimenter (DOLLERUP et GRAVER, 1985 ; LE BELLE et FONTAINE, 1987).

\section{Index oculaire (IO)}

L'accroissement du diamètre de l'œil est évalué par la mesure de l'index oculaire (1O). Les anguilles sédentaires ont un 10 compris entre 3,4 et 6,5 , les valeurs étant corrélées positivement avec le RGS. Une augmentation significative $(p<0,001)$ de l'IO est observée à l'argenture, la valeur moyenne passant de $4,9 \pm 0,08$ chez les anguilles sédentaires à $9,9 \pm 0,19$ chez les anguilles d'avalaison (valeurs individuelles comprises entre 6,8 et 12 ).

L'augmentation progressive de l'IO avec le RGS chez les anguilles sédentaires indique que l'accroissement du diamètre de l'oeil est un phénomène graduel initié dès le stade jaune en relation avec le développement ovarien. L'augmentation de l'lO, de même que celle du RGS, s'accentue à l'argenture.

Aucun recoupement des valeurs individuelles d'IO n'ayant été observé entre les anguilles sédentaires et migrantes, ce paramètre externe représente un critère fiable et d'accès facile sur le terrain, pour la caractérisation du stade argenté. De plus, la corrélation entre l'IO et le RGS chez les anguilles sédentaires, permet également d'utiliser ce critère pour évaluer l'état de développement ovarien au stade jaune.

Une augmentation de l'IO, en relation avec le diamètre ovocytaire, a été montrée par PANKHURST (1982) dans une étude comparative d'anguilles femelles non-migrantes et migrantes, capturées dans la rivière Parrett (Grande Bretagne). II a proposé une valeur seuil de l'IO de 6,5 pour caractériser le stade argenté, mais un certain degré de recoupement est observé avec le stade jaune. Une augmentation supplémentaire de l'IO est observée par PANKHURST (1982), en relation avec la poursuite du développement ovocytaire au cours de la maturation expérimentale. Dans une étude d'anguilles européennes en élevage, BEULLENS et al. (1997b) ont montré que les anguilles femelles jaunes ont un 10 moyen de $5,2 \pm 0,15$ (valeurs individuelles comprises entre 3,5 et 7,2 ) et les femelles argentées ont un 10 moyen de $9,08 \pm 0,39(5,7$ à 14,5) ; ils proposent une valeur seuil de 7,2 comme critère pour caractériser le stade argenté (62\% des argentées, $0 \%$ des jaunes).

Dans notre étude une valeur seuil $\geq 8$ permet de caractériser le stade argenté avec un haut degré de fiabilité (95\% des anguilles d'avalaison, $0 \%$ des anguilles sédentaires). 


\section{Paramètres endocriniens}

Hormones thyroïdiennes: thyroxine $\left(T_{4}\right)$ et triiodothyronine $\left(T_{3}\right)$

Les anguilles sédentaires ont des concentrations sériques de $\mathrm{T}_{4}$ comprises entre 1,3 et $31,3 \mathrm{ng} / \mathrm{ml}$ et de $T_{3}$ comprises entre 1,7 et $17,8 \mathrm{ng} / \mathrm{ml}$, sans relation avec la longueur du corps ni le RGS. Une augmentation significative $(p<0,001)$ de la teneur en $\mathrm{T}_{4}$ est observée lors de l'argenture, la moyenne passant de 12,5 0,63 à $17,3 \pm 1,11 \mathrm{ng} / \mathrm{ml}$. En revanche aucune variation de la teneur en $T_{3}$ n'est observée.

Chez le saumon, au cours de la smoltification, différents auteurs ont montré une activation de la fonction thyroïdienne, avec un pic transitoire de $T_{4}$ (pour revue : HOAR, 1988 ; BCEUF, 1993 ; DICKHOFF, 1993). En ce qui concerne $T_{3}$, les résultats sont beaucoup moins nets (BCEUF, 1993).

Nos résultats suggèrent une similitude dans l'activation de la fonction thyroïdienne, reflétée par une élévation de la $\mathrm{T}_{4}$, lors de l'argenture et de la smoltification. Cette activation thyroïdienne confère à ces deux phénomènes des caractéristiques de « métamorphose », telle qu'on l'observe chez les amphibiens.

La différence entre les valeurs moyennes de $T_{4}$ entre les anguilles sédentaires et d'avalaison est significative, mais le très haut degré de recoupement des valeurs individuelles $(96 \%)$ ne permet pas d'utiliser ce paramètre comme critère de l'argenture. L'activation de la fonction thyroïdienne étant sous la dépendance de l'hormone hypophysaire thyréotrope (TSH), nous purifions actuellement cette hormone chez l'anguille, afin de développer un système de dosage homologue et d'obtenir un nouveau paramètre de caractérisation de l'argenture.

\section{Hormone de croissance (GH)}

Les anguilles sédentaires et d'avalaison ont des concentrations sériques de $\mathrm{GH}$ comprises entre 0,8 et $15 \mathrm{ng} / \mathrm{ml}$, ces valeurs n'étant liées ni à la taille, ni au RGS, ni au stade. Nous ne pouvons cependant pas conclure que la sécrétion de $\mathrm{GH}$ ne varie pas. En effet, la sécrétion de $\mathrm{GH}$ étant pulsatile chez les Téléostéens comme chez les Mammifères, et la vitesse de disparition de $\mathrm{GH}$ dans le sang étant relativement rapide (demi-vie de $15 \mathrm{mn}$ chez Anguilla japonica: DUAN et HIRANO, 1991), les niveaux de GH sérique peuvent varier fortement avec le moment de prélèvement.

En ce qui concerne la teneur hypophysaire en $\mathrm{GH}$, les anguilles sédentaires ont des valeurs comprises entre 27 et $178 \mu \mathrm{g} /$ hypophyse, corrélées positivement à la longueur du corps mais pas au RGS. Cette corrélation avec la taille est en accord avec le rôle majeur de $\mathrm{GH}$ dans le contrôle de la croissance corporelle.

Une diminution significative $(p<0,001)$ de la teneur hypophysaire en GH est observée lors de l'argenture, avec une valeur moyenne passant de $82,5 \pm 3,7 \mu \mathrm{g} /$ hypophyse chez les anguilles sédentaires à $40,8 \pm 2,5 \mu \mathrm{g} / \mathrm{hyp}$ ophyse chez les anguilles d'avalaison. La chute de la teneur hypophysaire en $\mathrm{GH}$ chez l'anguille argentée est à relier à l'arrêt de la croissance corporelle à ce stade.

Malgré la différence significative des valeurs moyennes, le haut degré de recoupement $(52 \%)$ des valeurs individuelles de GH hypophysaire entre les anguilles sédentaires et migrantes ne permet pas d'utiliser ce paramètre comme critère de l'argenture. 


\section{Hormone gonadotrope (GtH)}

Les anguilles sédentaires ont des teneurs hypophysaires de $\mathrm{GtH}$ comprises entre 0,2 et $12 \mathrm{ng} /$ hypophyse, corrélées positivement avec la longueur du corps et le RGS. La relation avec le développement ovarien (lié lui-même à la taille) suggère une mise en route progressive de l'axe gonadotrope dès le stade jaune.

Une très forte augmentation ( $x$ 25) de la teneur hypophysaire en GtH est observée lors de l'argenture, la valeur moyenne passant de 2,1 $\pm 0,3 \mathrm{ng} / \mathrm{hypophyse}$ chez les anguilles sédentaires à $51,4 \pm 4,2$ ng/hypophyse chez les anguilles d'avalaison. Cette amplification de la teneur hypophysaire en GtH conforte les caractéristiques d'initiation de la puberté spécifiques de l'argenture et non retrouvées dans la smoltification.

De plus, un très faible degré de recoupement est observé pour les valeurs individuelles $(2,5 \%)$, si bien qu'une valeur seuil $\geq 15 \mathrm{ng} /$ hypophyse peut être retenue comme critère de caractérisation du stade argenté avec une forte fiabilité $(97 \%$ des anguilles d'avalaison, $0 \%$ des anguilles sédentaires).

\section{CONCLUSION}

Cette étude montre que l'argenture de l'anguille est un phénomène complexe comportant à la fois des caractères de métamorphose similaires à la smoltification (livrée, osmorégulation (cf. Introduction), élévation de l'hormone thyroïdienne, $T_{4}$ ), et des caractères d'initiation de la puberté (développement ovarien, augmentation de l'hormone gonadotrope, GtH), ainsi que d'autres changements physiologiques pouvant être reliés à la phase de reproduction, tels que l'entrée en jeûne et l'arrêt de la croissance (avec une baisse de l'hormone de croissance, $\mathrm{GH}$ ).

Parmi les paramètres anatomiques et endocriniens étudiés, certains peuvent être retenus comme critères pour la caractérisation du stade argenté, soit sur l'animal vivant (index oculaire), soit après sacrifice des anguilles (rapport gonado-somatique, rapport tractus digestif-somatique, GtH hypophysaire).

D'autres paramètres, qui varient aussi lors de l'argenture, ne peuvent cependant pas être retenus comme critères, du fait du haut degré de recoupement des valeurs individuelles entre les anguilles sédentaires et d'avalaison ( $T_{4}$ circulante, $G H$ hypophysaire).

Nous appliquons actuellement les critères retenus pour le suivi de populations sauvages d'anguilles dans deux écosystèmes différents (Lac de Grand-Lieu et Rhin), dans le cadre d'études en coopération avec le CSP et le CEMAGREF. Nos travaux s'orientent également vers la recherche et la mise au point de nouvelles méthodes d'évaluation de l'argenture, avec des critères supplémentaires anatomiques et endocriniens.

\section{REMERCIEMENTS}

Cette étude a été réalisée grâce à la Convention CSP nº 94/357 et à l'intervention de la Délégation Régionale $n^{\circ} 1$ du CSP pour les pêches électriques. Nous tenons à remercier très sincèrement le CSP et son Responsable des Relations Scientifiques, E. VIGNEUX, pour leur action de soutien, d'incitation et de coordination des recherches sur l'Anguille en France. 


\section{BIBLIOGRAPHIE}

BEULLENS K., EDING E.H., GILSON P., OLLEVIER F., KOMEN J., RICHTER C.J.J., 1997a. Gonadal differentiation, intersexuality and sex ratios of European eel (Anguilla anguilla L.) maintained in captivity. Aquaculture, 153, 135-150.

BEULLENS K., EDING E.H., OLLEVIER F., KOMEN J., RICHTER C.J.J., 1997b. Sex differentiation, changes in length, weight and eye size before and after metamorphosis of European eel (Anguilla anguilla L.) maintained in captivity. Aquaculture, 153, 151-163.

BCEUF G., 1993. Salmonid smolting : a pre-adaptation to the oceanic environment. In : RANKIN J.C. and JENSEN F.B. (Eds.), Fish Ecophysiology, Chapman and Hall, London, 105-135.

BURZAWA-GERARD E., KERDELHUÉ B., 1978. Etude par radioimmunologie des propriétés des immunosérums de l'hormone gonadotrope de la carpe (Cyprinus carpio) et de ses sous unités. Ann. Biol. Anim. Biochem. Biophys., 18, 773-780.

COLOMBO G., GRANDI G., ROSSI R., 1984. Gonad differentiation and body growth in Anguilla anguilla L. J. Fish Biol., 24, 215-228.

COLOMBO G., GRANDI G., 1996. Histological study of the development and sex differentiation of the gonad in the European eel. J. Fish Biol., 48, 493-512.

DICKHOFF W.W., 1993. Hormones, metamorphosis, and smolting. In : SCHREIBMAN M.P., SCANES C.G., PANG P.K.T., The endocrinology of growth, development, and metabolism in vertebrates, Academic Press, San Diego, 519-540.

DOLLERUP J., GRAVER C.M., 1985. Repeated induction of testicular maturation and spermiation, alternating with periods of feeding and growth in silver eels, Anguilla anguilla L. Dana, 4, 19-39.

DUAN C., HIRANO T., 1991. Plasma kinetics of growth hormone in the Japanese eel, Anguilla japonica. Aquaculture, 95, 179-188.

DUFOUR S., 1994. Neuroendocrinologie de la reproduction de l'anguille : de la recherche fondamentale aux problèmes appliqués. Bull. Fr. Pêche Piscic., 335, 187-211.

DUFOUR S., DELERUE-LE BELLE N., FONTAINE Y.A., 1983. Development of a heterologous radioimmunoassay for eel (Anguilla anguilla) gonadotropin. Gen. Comp. Endocrinol., 49, 404-413.

ELIE P., ROCHARD E., 1994. Migration des civelles d'anguilles (Anguilla anguilla L.) dans les estuaires ; modalités du phénomène et caractéristiques des individus. Bull. Fr. Pêche Piscic., 335, 81-98.

FONTAINE M., 1975. Physiological mechanisms in the migration of marine and amphihaline fish. Adv. Mar. Biol., 13, 241-355.

FONTAINE M., 1983. La vie de notre Société hier et demain. Introduction à une écophysiologie d'anticipation. Bull. Soc. Ecophysiologie, 8, 63-69.

FONTAINE M., BERTRAND E., LOPEZ E., CALLAMAND O., 1964. Sur la maturation des organes génitaux de l'anguille femelle (Anguilla anguilla L.) et l'émission spontanée des oeufs en aquarium. C. R. Acad. Sci. Paris, 259, 2907-2910.

FONTAINE Y.A., 1989. Les Anguilles : migration et reproduction. Oceanis, 15, 197-206.

FONTAINE Y.A., 1994. L'argenture de l'anguille : métamorphose, anticipation, adaptation. Bull. Fr. Pêche Piscic., 335, 171-185.

FONTAINE Y.A., DUFOUR S., ALINAT J., FONTAINE M., 1985. L'immersion prolongée en profondeur stimule la fonction hypophysaire gonadotrope de l'anguille européenne (Anguilla anguilla L.) femelle. Ann. Biol. Anim. Bioch. Biophys., 18, 805-811. 
FONTAINE Y.A., DUFOUR S., 1991. The eels: from life cycle to reproductive endocrinology. Bull. Inst. Zool., Academia Sinica, Monograph, 16, 237-248.

FONTAINE Y.A., PISAM M., LE MOAL C., RAMBOURG A., 1995. Silvering and gill " mitochondriarich" cells in the eel. Anguilla anguilla. Cell Tissue Res., 281, $465-471$.

HOAR W.S., 1988. The physiology of smolting salmonids. In : Fish Physiology, HOAR W.S. and RANDALL D.J. (Eds.), Academic Press, New York, 275-343.

KLECKNER R.C., 1980. Swimbladder volume maintenance related to initial migratory depth in silver phase Anguilla rostrata. Science, 208, 1481-1482.

KLECKNER R.C., KRUEGER W.H., 1981. Changes in swimbladder retial morphology in Anguilla rostrata during premigration metamorphosis. J. Fish Biol., 18, 569-577.

LE BELLE N., FONTAINE M., 1987. Toutes les anguilles mâles et femelles peuvent-elles frayer une seconde fois dans la nature ? Ichtyophysiol. Acta, 11, 7-11.

LECOMTE-FINIGER R., 1984. Cycle biologique et problématique de l'Anguille européenne (Anguilla anguilla L., 1758). Point actuel des connaissances. Ann. Biol., 23, 339-366.

LECOMTE-FINIGER R., 1990. Métamorphose de l'anguille jaune en anguille argentée (Anguilla anguilla L.) et sa migration catadrome. Ann. Biol., 29, 183-194.

LECOMTE-FINIGER R., 1994. Contribution de l'otolithométrie à l'étude de la dynamique de la migration larvaire de l'anguille européenne Anguilla anguilla. Bull. Fr. Pêche Piscic., 335, 17-31.

LELOUP J., DE LUZE A., 1980. Prolactine et hormones thyroïdiennes chez l'anguille (Anguilla anguilla L.). C. R. Acad. Sci., 291, 87-90.

MARCHELIDON J., SCHMITZ M., HOUDEBINE L.M., VIDAL B., LE BELLE N., DUFOUR S., 1996. Development of a radioimmunoassay for European eel growth hormone and application to the study of silvering and experimental fasting. Gen. Comp. Endocrinol., 102, 360-369.

PANKHURST N.W., 1982a. Relation of visual changes to the onset of sexual maturation in the European eel Anguilla anguilla (L.). J. Fish Biol., 21, 127-140.

PANKHURST N.W., 1982b. Changes in body musculature with sexual maturation in the European eel. J. Fish Biol., 21, 417-428.

PANKHURST N.W., LYTHGOE J.N., 1983. Changes in vision and olfaction during sexual maturation in the European eel. J. Fish Biol., 23, 229-240.

SCHMIDT J., 1922. The breeding places of the eel. Phil. Trans. R. Soc., 211 (B), 179-208.

SORENSEN P.W., PANKHURST N.W., 1988. Histological changes in the gonad, skin ; intestin and olfactory epithelium for the artificially-matured male American eel, Anguilla rostrata. J. Fish Biol., 32, 297-307.

TESCH F.W., 1977. The eel : biology and management of anguilloid eels. In : GREENWOOD P.H. (ed.), Chapman and Hall, London, 434 p.

VOLLESTAD L.A., JONSSON B., 1986. Life history characteristics of the European eel in the Imsa River Norway. Trans. Am. Fish. Soc., 115, 864-871. 